\title{
Smaller global and regional carbon emissions from gross land use change when considering sub-grid secondary land cohorts in a global dynamic vegetation model
}

Chao Yue et al.

Correspondence to: Chao Yue (chao.yue@1sce.ipsl.fr)

The copyright of individual parts of the supplement might differ from the CC BY 4.0 License. 


\section{Backcasting historical PFT maps and generation of land use change matrices}

2 The processes to reconcile LUH1 land use transitions and the 2005 ORCHIDEE-compatible PFT map

3 based on ESA CCI land cover map are summarized in Fig. S1. All land use transitions, as well as

4 distribution of land use types or PFTs over model grid cells, are expressed as fraction of grid cell

5 (unitless). The original land use transition matrices provided by LUH1 is M1. In Step S1, transitions

6 from primary and secondary natural land are grouped together to derive the matrix M2, before they are

7 split into forest and natural grassland. Next, land use transitions are separated into two types (Step S2)

8 bearing the form of M3, which is further split into two matrices in Step S3: the net land use change

9 matrix (M5), and the land turnover matrix (M4) that represents bi-directional equal-area transitions

10 between two land cover types. Land turnover transitions are obtained by extracting the minimum value

11 between two reverse land use transitions (secondary land and crop or pasture), with the rest (after

12 subtracting this minimum) as the net transition. Here, the land turnover is limited to the tropical

13 regions, as in the original LUH1 data.

In a circular process comprising the steps of S4 and S5, the net transition matrices for 1500-2004 are used with the 2005 PFT map as a starting point to iteratively backcast PFT map time series of 15002004 (Fig. S1). To make it simple, net transitions between pasture and cropland are ignored. Then natural lands are split into forest and natural grassland. This is described in Step S4, which generates the matrix M6. When splitting natural land into forest and grassland, increment in cropland or pasture is assumed as half being from forest, half from grassland; decrease in cropland is assumed to be occupied first by forest and then by grassland; decrease in pasture is assumed to be occupied half by forest and half by grassland. However, these rules must be consistent with the backcasting-dervied PFT map. For example, forest fraction in the previous year, which is going to be calculated as the sum of current-year forest lost (due to conversion to cropland) and its existing fraction, should simply not exceed unity (i.e., 100\% of the grid cell area). In the opposite case, where forest fraction should be calculated by subtracting a value from the current year fraction (because of cropland abandonment), the obtained value should not be lower than zero. These rules, despite simple ones at first glance, turn the backcasting historical PFT maps into a complex task with a lot compromises. In the worst case, compromises could not be made and part of the net transitions prescribed in the LUH1 data has to be ignored. This loop of generating PFT map for the former year using the current-year PFT map and the net transition matrix between the two years, finally generates annual time series of spatially resolved distribution of forest, natural grassland, cropland and pasture. The disaggregation of these four vegetation types further into model PFTs is done by assuming that their relative fractions conform to those for the year of 2005. 
The next step is to make land turnover matrices being consistent with the backcasting-derived PFT map for each year. This is relatively easy to do. First, we restrict cropland-pasture land turnover rates within the minimum of existing fractions between cropland and pasture. Second, we restrict the turnover rates between secondary natural land and cropland (or pasture) within the minimum of existing fractions between secondary natural land and cropland (or pasture). Then the secondary natural land transitions are split into forest and grassland according to their current relative fractions. This process (Step S6) finally generates Matrix M7. The last task is to generate the matrices for wood harvest. Harvest information as grid cell fraction is provided for primary and secondary forest in LUH1 and maintained as the model input. However, the sum of their fractions is limited within existing forest area. Forest harvest matrices are represented as M8.

Fig. S2 - Fig. S6 explores the land use transition matrices over the globe after the backcasting constraint. Significant loss of information compared to the original LUH1 data happens for the case of net transition from natural land to pasture, where about $35 \%$ of natural land loss to pasture was suppressed (Fig. S2). This is an inevitable outcome given the irreconcilable discrepancy in the spatial distribution of land cover between the LUH1 and ESA CCI land cover map, as is detailed by Peng et al. (2017). However, areas for the four basic land use types, i.e., forest, grassland, cropland and pasture from our backcasting algorithm generally agree with those by Peng et al. (2017) (Fig. S3), who made the similar backcasting but used the cropland and pasture distribution map rather than land use transitions from LUH1 data, with forest area for 1850-2009 being constrained by data in Houghton (2003) based on national forest area statistics. Loss of land turnover information is less significant, with a historical maximum of $\sim 30 \%$ for the transitions between secondary land and pasture (Fig. S4). Note that wood harvest by LUH1 data occurs for most forest biomes in the world, land turnover (literally shifting cultivation) is limited within tropical regions (Fig. S5). Finally, areas subject to wood harvest suffer almost no loss during the constraint in the backcasting process (Fig. S6). 

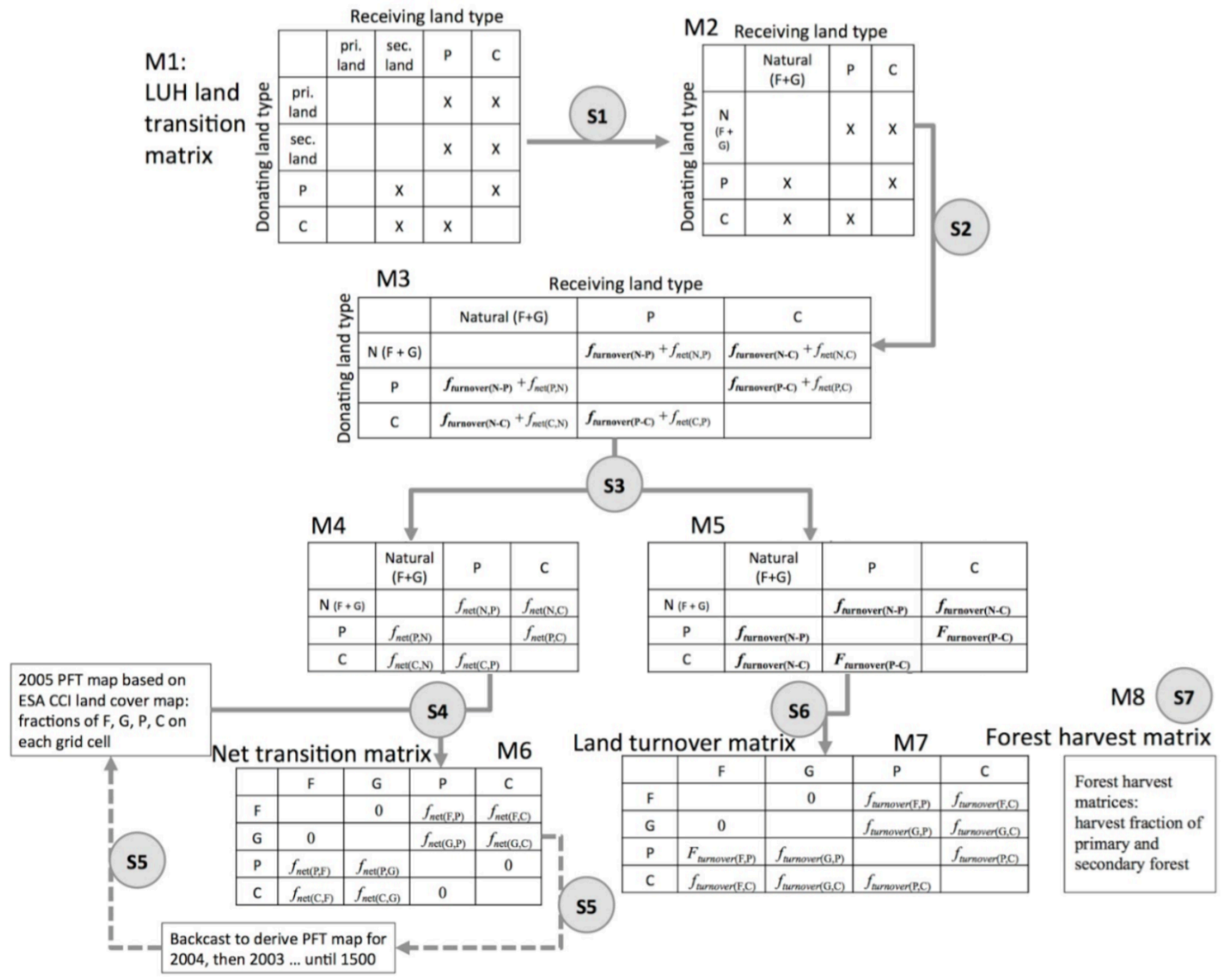

S3

62 Fig. S1 Diagram illustrating the construction of time series of land transition matrices for net land use

63 change, land turnover and wood harvest from LUH1 data set, and the backcasting of historical PFT

64 map time series based on an ORCHIDEE-compatible PFT map, which is further derived from

65 European Space Agency (ESA) Climate Change Initiative (CCI) land cover map covering the period

66 of 2003-2008. M1 to M8 represent different matrices. M1 to M5 are intermediate matrices, M6

67 indicates the net transition matrix, M7 indicates the land turnover matrix, and M8 indicates forest

68 harvest matrix. S1 to S5 represent different steps involved in deriving the M6-M8. S4 and S5 show a

69 circular process of backcasting historical PFT map time series as constrained by net land use change

70 matrices. Blank cells in the matrix indicate no transition occurring, while cells marked as ' $x$ ' shows

71 occurring transitions. 


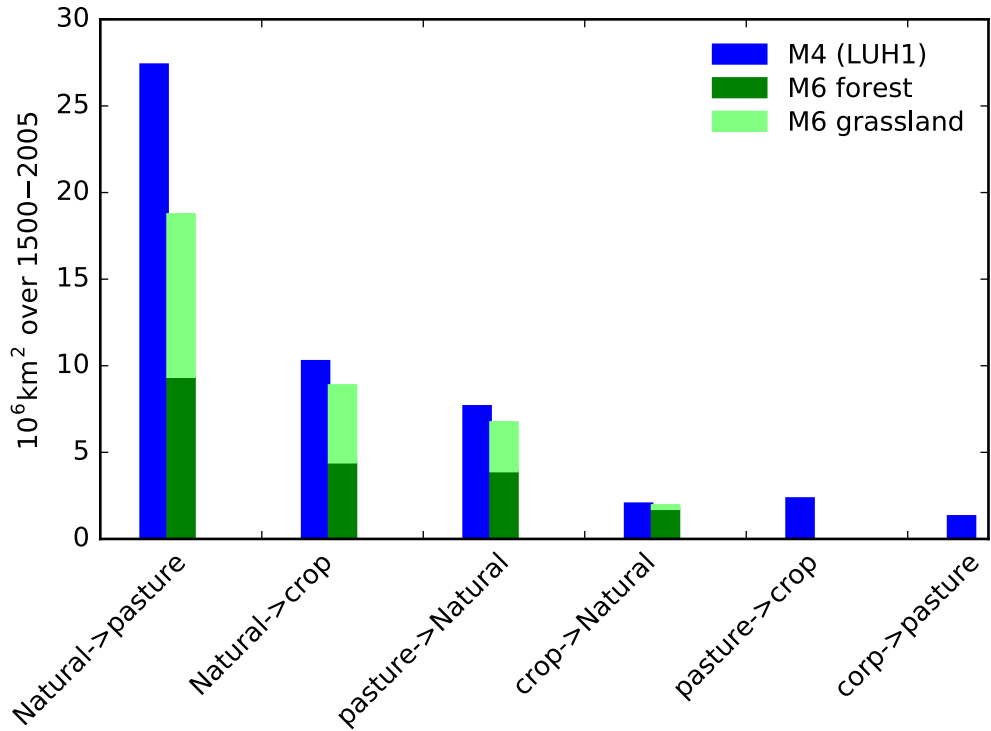

75 Fig. S2 The separation of natural land into forest (dark geen) and natural grassland (light green) in the net land use transition matrices of M6, after the compromise with the 2005 PFT map, in comparison with the original values in LUH1 data set (M4). See Fig. S1 for details about matrices of M4 and M6.
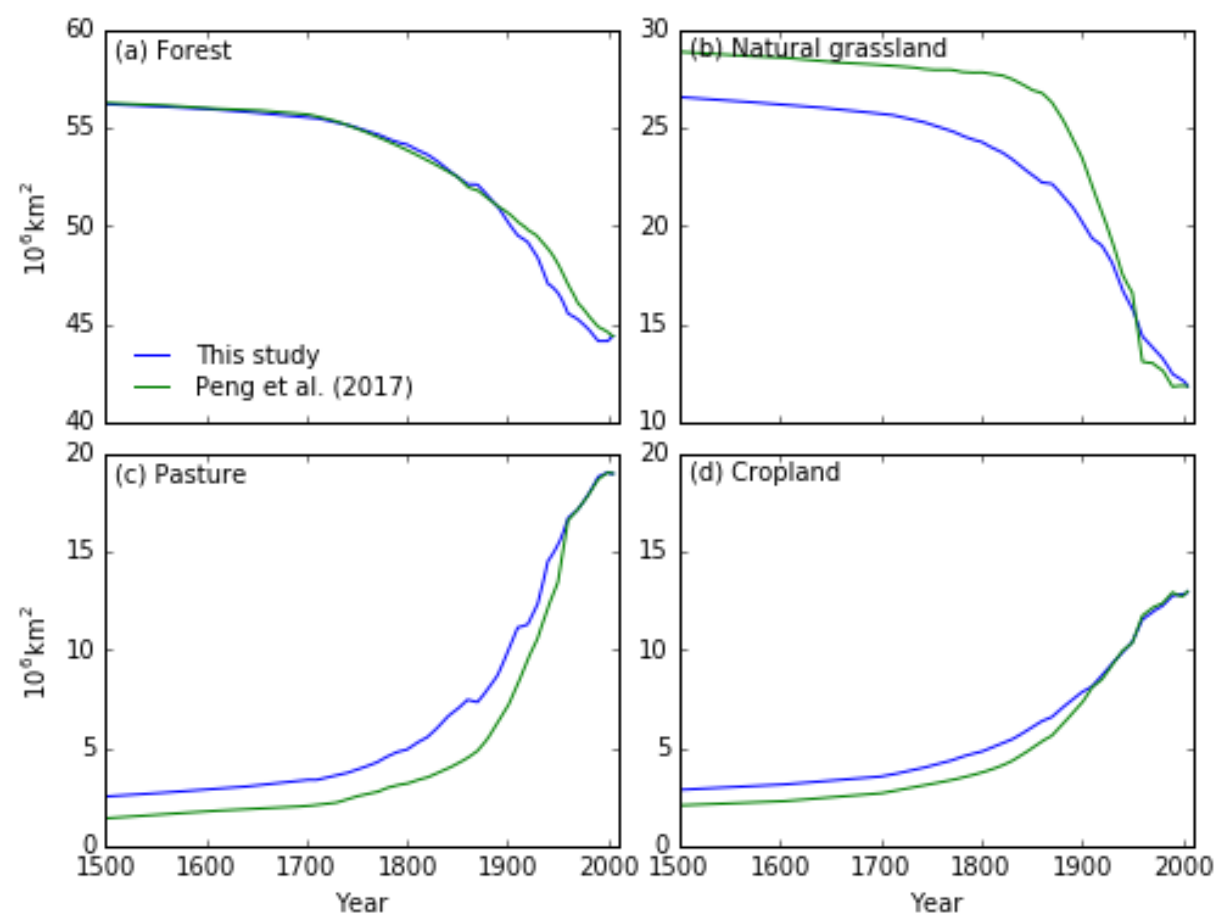

Fig. S3 The changes in areas of forest, natural grassland, pasture and cropland in comparison to Peng

81 et al. (2017), who made the similar backcasting but used the cropland and pasture distribution map

82 rather than land use transitions in LUH1 data, with forest area for 1850-2009 being constrained by

83 data in Houghton (2003) based on national forest area statistics. 

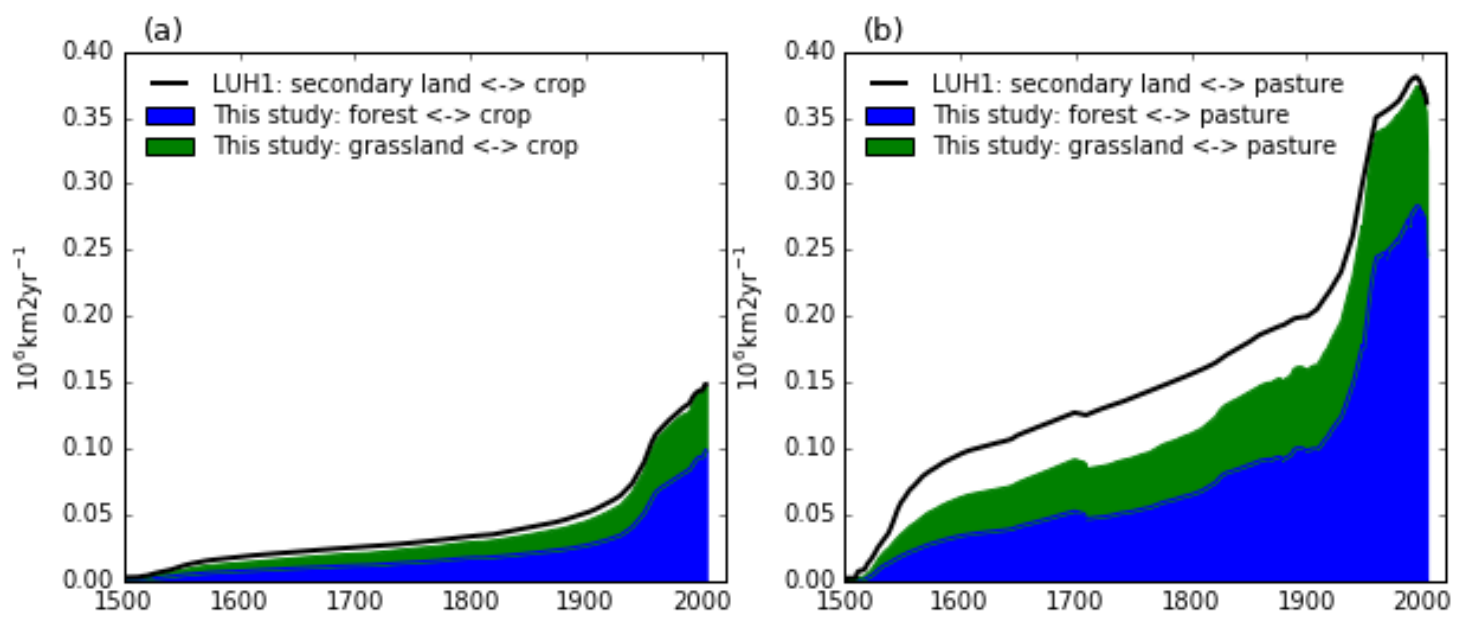

Fig. S4 Land turnover (i.e., shifting cultivation) originally contained in the LUH1 data indicated as

90 after constraint in our backcasting algorithm (M7).

91

(a) Land turnover (mean annual of 1501-2005)

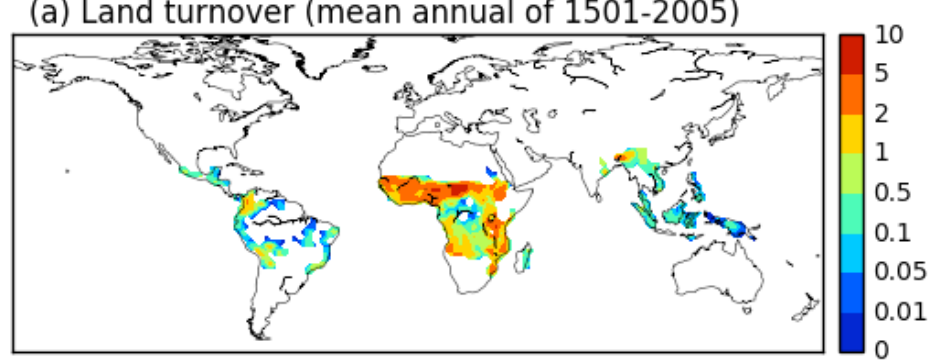

(b) Wood harvest (mean annual of 1501-2005)

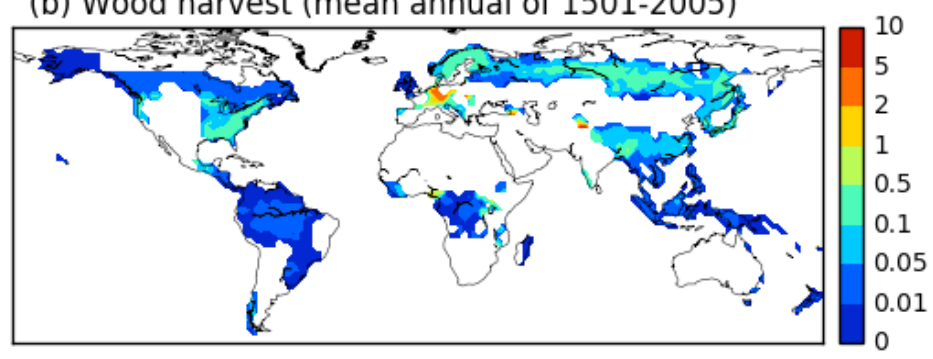

Fig. S5 Annual land turnover or forest harvest in percentage of grid cell area (\%) averaged over 15012005. 

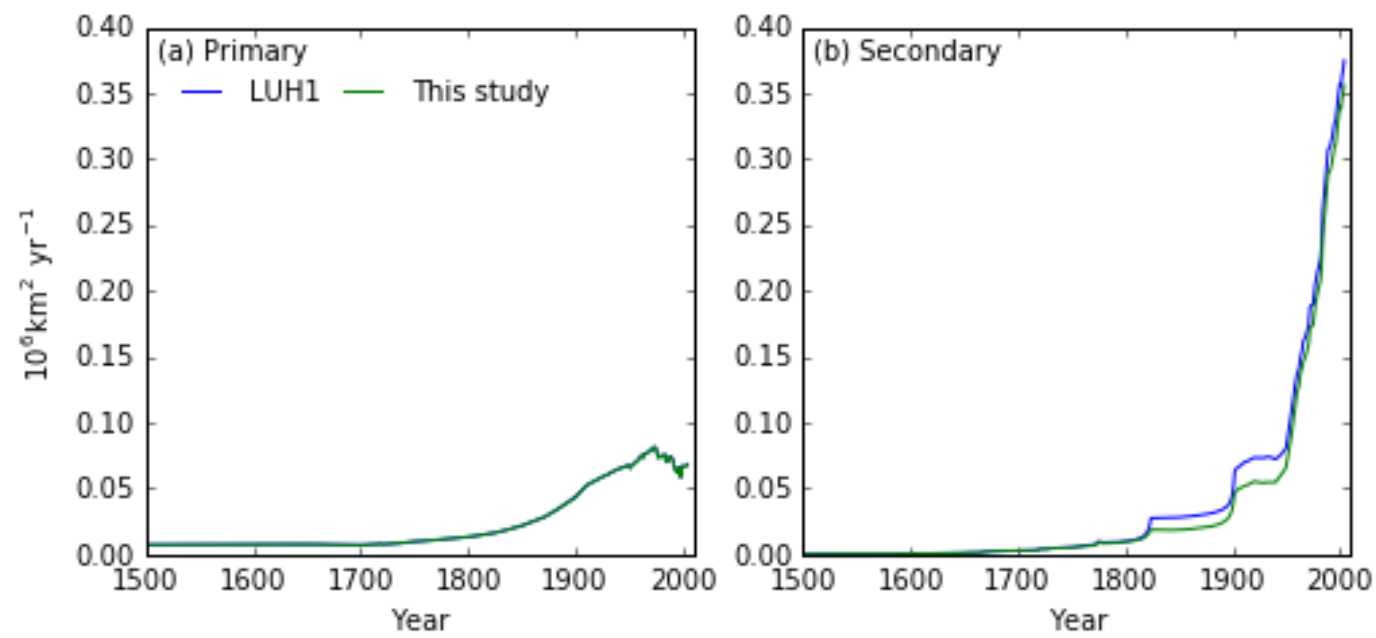
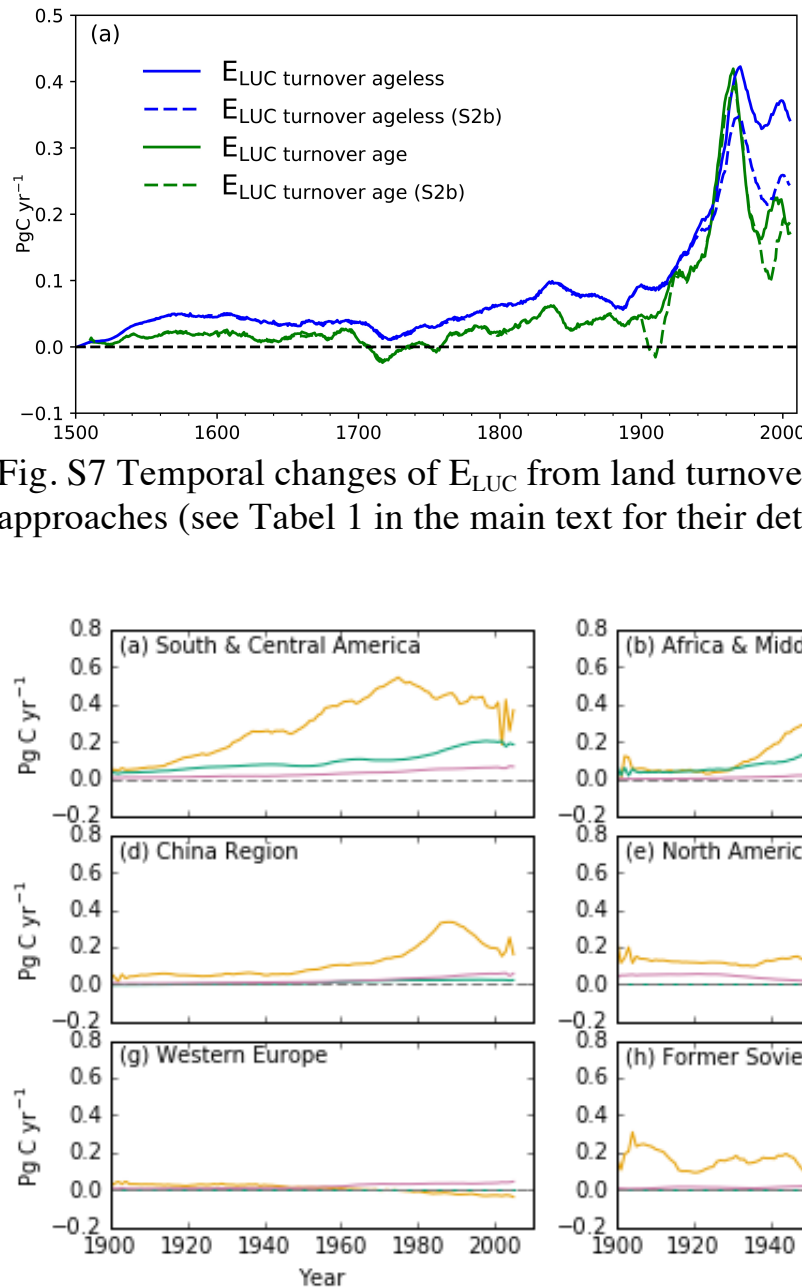

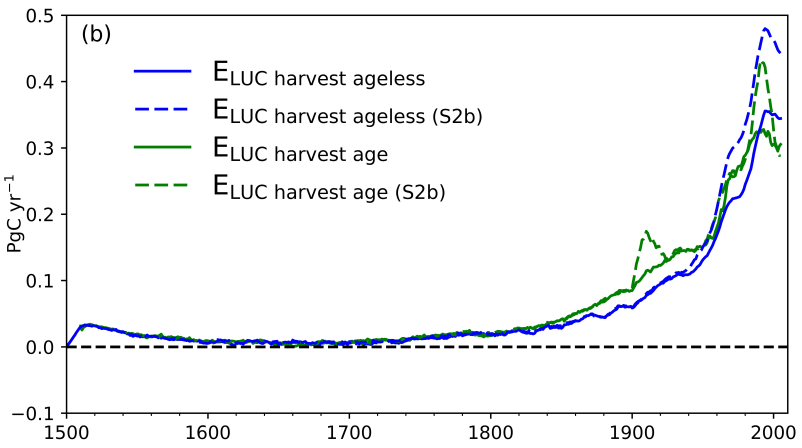

Fig. S7 Temporal changes of $\mathrm{E}_{\mathrm{LUC}}$ from land turnover and wood harvest quantified by different approaches (see Tabel 1 in the main text for their detailed definitions).
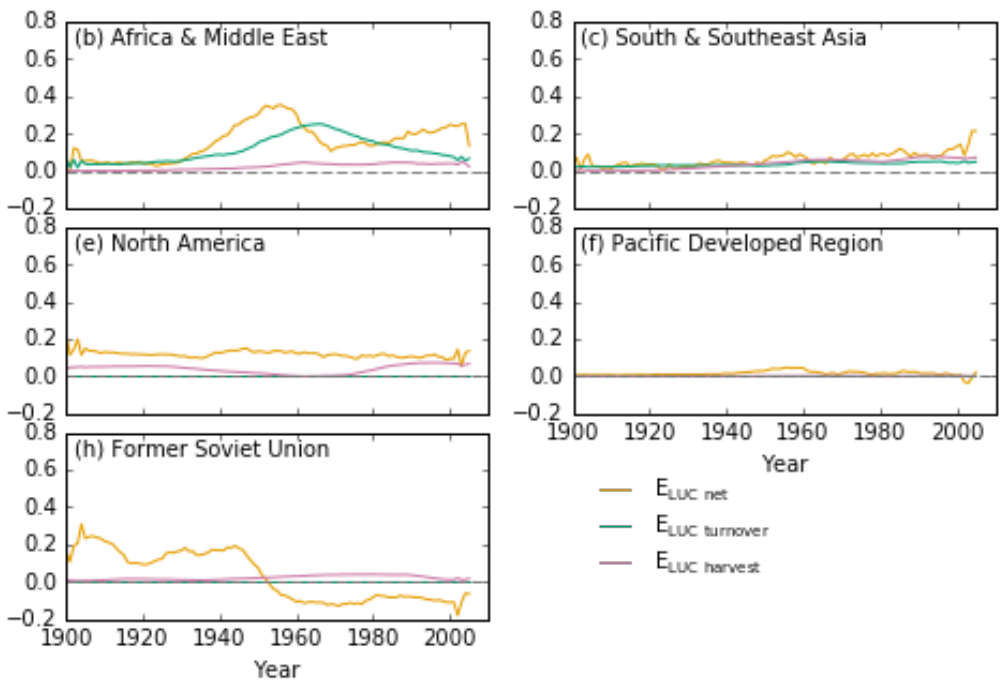

105 Fig. S8 Temporal pattern of regional land use change emissions $\left(\mathrm{E}_{\mathrm{LUC}}\right)$ from different LUC processes

106 for the $S_{\text {ageless }}$ simulation (i.e., without sub-grid age dynamics). The relative patterns of $E_{L U C}$ net, $E_{L U C}$

107 turnover and $\mathrm{E}_{\mathrm{LUC}}$ harvest are similar in $\mathrm{S}_{\text {age }}$ simulation (with sub-grid age dynamics) and thus are not shown

108 separately. Refer to Fig. 5 in the main text for the spatial extents of different regions. 


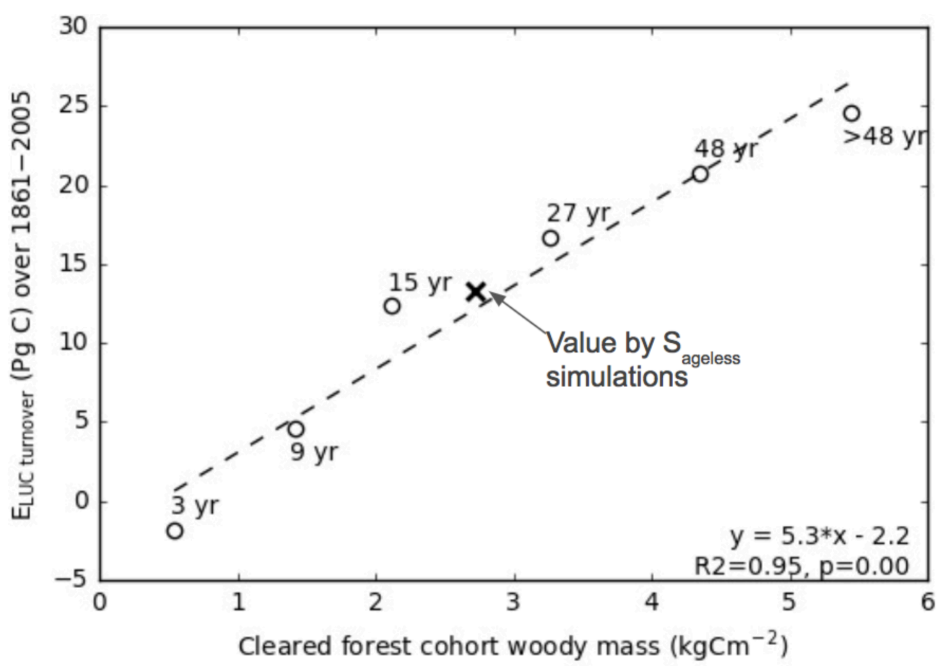

111 Fig. S9 Sensitivity of $E_{\text {LUC turnover, age }}$ over 1861-2005 to the rotation length of shifting cultivation in

112 Africa expressed in terms of forest woody mass. The forest ages corresponding to different woody

113 masses are also shown. The cross sign indicates $\mathrm{E}_{\mathrm{LUC}}$ turnover, ageless as the difference in NBP between the

$114 \mathrm{~S} 1_{\text {ageless }}$ and $\mathrm{S} 2_{\text {ageless }}$ simulations, assuming the cleared woody mass as $50 \%$ of the maximum spin-up

115 woody mass.

116

117 Table S1 Comparisons of cumulative LUC emissions from our studies and several previous studies,

118 adapted from Table 2 of Hansis et al. (2015).

\begin{tabular}{|c|c|c|c|c|}
\hline Reference & Time period & LUC data set & LUC implementation ${ }^{a}$ & $\begin{array}{l}\text { Cumulative } \\
E_{\text {Luc }}(\mathrm{Pg} \mathrm{C})\end{array}$ \\
\hline $\begin{array}{l}\text { This study (With age } \\
\text { dynamics, biomass adjusted) }\end{array}$ & 1850-2005 & Hurtt et al. (2011) & $G T, W H$ & $161-194$ \\
\hline $\begin{array}{l}\text { This study (With age } \\
\text { dynamics, original) }\end{array}$ & 1850-2005 & Hurtt et al. (2011) & $G T, W H$ & 147 \\
\hline $\begin{array}{l}\text { This study (No age dynamics, } \\
\text { biomass adjusted) }\end{array}$ & 1850-2005 & Hurtt et al. (2011) & $G T, W H$ & $174-207$ \\
\hline $\begin{array}{l}\text { This study (No age dynamics, } \\
\text { original) }\end{array}$ & 1850-2005 & Hurtt et al. (2011) & $G T, W H$ & 158 \\
\hline Hansis et al. 2015 & 1850-2005 & Hurtt et al. (2011) & GT, WH, AProp & 261 \\
\hline $\begin{array}{l}\text { Houghton et al. (2012) } \\
\text { multimodel range }\end{array}$ & 1920-1999 & various & various & $72-115$ \\
\hline $\begin{array}{l}\text { Houghton (personal } \\
\text { communication) }\end{array}$ & 1850-2010 & FAO/FRA (on regional basis) & GT, WH, APasture & 182 \\
\hline Shevliakova et al. (2013) & 1850-2005 & Hurtt et al. (2011) & GT, WH, AProp & 210 \\
\hline Jain et al. (2013) & 1900-2005 & various & NT, WH, AProp & $160-178$ \\
\hline Stocker et al. (2014) & 1850-2004 & Hurtt et al. (2011) & GT, WH, AProp & 171 \\
\hline Wilkenskjeld et al. (2014) & 1850-2005 & Hurtt et al. (2011) & GT, WH, APasture & 225 \\
\hline Gasser and Ciais (2013), Hurtt & 1850-2005 & $\begin{array}{l}\text { Hurtt et al. (2011) (on } \\
\text { regional basis) }\end{array}$ & GT, WH, AProp & 294 \\
\hline $\begin{array}{l}\text { Gasser and Ciais (2013), } \\
\text { Hurtt/Houghton }\end{array}$ & 1850-2005 & $\begin{array}{l}\text { Hurtt et al. (2011) (on } \\
\text { regional basis) }\end{array}$ & GT, WH, AProp & 203 \\
\hline
\end{tabular}

${ }^{a}$ Implementation choices refer to gross (subgrid-scale) versus net LUC transitions (GT versus NT), if wood harvest is included (WH) and if agricultural land is taken proportionally from natural vegetation types (AProp) or if pasture is preferentially taken from grasslands (APasture). In our study, agricultural land is taken equally from forest and natural grassland, then proportionally within all forest or grassland PFTs. 


\section{References:}

123 Hansis E, Davis SJ, Pongratz J (2015) Relevance of methodological choices for accounting of land use 124 change carbon fluxes. Global Biogeochemical Cycles, 29, $2014 \mathrm{~GB} 004997$.

125 Houghton RA (2003) Revised estimates of the annual net flux of carbon to the atmosphere from 126 changes in land use and land management 1850-2000. Tellus B, 55, 378-390.

127 Peng S, Ciais P, Maignan F, Li W, Chang J, Wang T, Yue C (2017) Sensitivity of land use change 128 emission estimates to historical land use and land cover mapping. Global Biogeochemical Cycles, 31, $1292015 \mathrm{~GB} 005360$. 